\title{
TÉCNICA DE LAVAGEM DE EQUIPOS APÓS ADMINISTRAÇÃO DE MEDICAMENTOS: ANÁLISE DE DIPIRONA EM VOLUME RESIDUAL POR VOLUMETRIA DE OXIRREDUÇÃO.
}

\section{TEAM WASHING THECNIQUE AFTER DRUG ADMINISTRATION: DIPYRONE ANALYSIS IN RESIDUAL VOLUME BY OXYREDUCTION VOLUMETRY.}

\author{
Ana Laura de Oliveira Gondim¹, Maria Amélia Estrela Albergaria²
}

Submetido: $11 / 02 / 2021$
Aprovado: $01 / 03 / 2021$

\section{RESUMO}

Alguns riscos estão associados na escolha da via intravenosa como o surgimento de incompatibilidades, sendo que o produto resultante pode afetar a segurança e eficácia terapêutica. Os medicamentos administrados precisam conter a dose que foi prescrita, devendo ser infundido todo conteúdo a fim de garantir que o paciente receba a dose correta. No entanto, é comum que a quantidade de medicamento não chegue à veia do paciente, ficando retida dentro da extensão do equipo, denominado volume residual. No final da infusão do medicamento é possível lavar o equipo, proporcionando ao paciente uma resposta terapêutica mais efetiva, porém na prática clínica observase que a lavagem nem sempre acontece. A lavagem do equipo é fundamental para garantia da infusão completa do medicamento evitando subdoses e incompatibilidades. O objetivo deste trabalho é determinar o volume necessário de solvente para lavar equipos de infusão volumétrica utilizados em pediatria preenchidos com solução injetável de dipirona. A metodologia utilizada para detectar dipirona é a iodimetria. As análises consistem em lavar o equipo até que se quantifique zero da solução injetável. As análises demonstraram que o volume de soro necessário para lavagem de equipos é de $15 \mathrm{~mL}$. Após a lavagem do equipo com esse volume, a dipirona não foi detectada na solução de lavagem. De acordo com o presente estudo o volume de soro necessário para lavagem de equipo é de $15 \mathrm{~mL}$. Após a lavagem do equipo com esse volume, a dipirona não foi detectada na solução de lavagem.

PALAVRAS-CHAVE: Lavagem. Equipos. Subdose. Incompatiblidade. Dipirona.

\begin{abstract}
Some risks are associated with the choice of intravenous route, such as the appearance of incompatibilities, and the resulting product can affect safety and therapeutic efficacy. The medications administered must contain the dose that was prescribed, and all content must be infused to ensure that the patient receives the correct dose. However, it is common that the amount of medication does not reach the patient's vein, being retained within the extension of the equipment, called residual volume. At the end of the medication infusion, it is possible to wash the equipment, providing the patient with a more effective therapeutic response, however in clinical practice it is observed that washing does not always happen. The washing of the equipment is essential to guarantee the complete infusion of the medication, avoiding underdoses and incompatibilities. The objective of this work is to determine the necessary volume of solvent to wash volumetric infusion equipment used in pediatrics filled with an injectable dipyrone solution. The methodology used to detect dipyrone is iodimetry. The analyzes consist of washing the equipment until zero of the solution for injection is quantified. The analyzes showed that the volume of serum needed for washing equipment is $15 \mathrm{ml}$. After washing the equipment with this volume, dipyrone was not detected in the washing solution. According to the present study, the volume of serum needed for washing the equipment is $15 \mathrm{ml}$. After washing the equipment with this volume, dipyrone was not detected in the washing solution.
\end{abstract}

KEYWORDS: Wash. Teams. Subdose. Incompatibility. Dipyrone.

\footnotetext{
1 UNICEPLAC - https://orcid.org/0000-0002-1915-6545 - analauragondim@hotmail.com

2 Search ror.org - https://orcid.org/0000-0002-9226-1157 - maria.estrela@uniceplac.edu.br
} 


\section{RECIMA21 - REVISTA CIENTÍFICA MULTIDISCIPLINAR}

TÉCNICA DE LAVAGEM DE EQUIPOS APÓS ADMINISTRACÃO DE MEDICAMENTOS: ANÁLISE DE DIPIRONA EM VOLUME RESIDUAL POR VOLUMETRIA DE OXIRREDUÇÃO. Ana Laura de Oliveira Gondim, Maria Amélia Estrela Albergaria

\section{INTRODUÇÃO}

A administração de medicamentos é feita desde o preparo do medicamento até a administração no paciente com o objetivo de alcançar efeitos terapêuticos. Normas e rotinas são necessárias para normatizar o trabalho em unidades de saúde, visando obter organização e controle (COSTA et al., 2009).

Os medicamentos podem ser administrados por diferentes vias. As vias incluem as vias oral, sublingual ou bucal, retal, de inalação, tópica e parenteral. A escolha da via adequada depende da conveniência e da necessidade. A administração parenteral inclui as vias intravenosa, intramuscular e subcutânea (GENNARO, 2014).

A via intravenosa é frequentemente utilizada no ambiente hospitalar sendo essencial quando não é possível utilizar outra via de administração ou quando é necessário o início rápido do efeito farmacológico. Alguns riscos estão associados na escolha da via intravenosa como o surgimento de incompatibilidades entre os medicamentos utilizados (SECOLI et al., 2009). As incompatibilidades entre os medicamentos ocorrem devido às interações físico-químicas entre medicamento e medicamento, solução, recipiente ou outras substâncias, sendo que o produto resultante pode afetar a segurança e eficácia terapêutica (PRELHACOSKI, SILVA e COMARELLA, 2015).

Os medicamentos administrados precisam conter a dose que foi prescrita ao paciente, devendo ser infundido todo conteúdo do frasco a fim de garantir que o paciente receba a dose correta. No entanto, é comum que a quantidade de medicamento não chegue à veia do paciente, ficando retida dentro da extensão do equipo, denominado volume residual. Muitas vezes esse volume é desprezado junto com o equipo, deixando de garantir a dose certa (SILVA, FURLAN, WEHBE, 2011). Se o volume residual não for considerado pode ocorrer um erro de dosagem trazendo prejuízo ao paciente e diminuindo o efeito terapêutico desejado (COSTA et al., 2009).

No final da infusão do medicamento é possível lavar o equipo, o volume residual encontrado tem importância significativa, representando até $15 \%$ da dose medicamentosa prescrita quando 0 volume total do medicamento for igual ou inferior a $100 \mathrm{~mL}$. A adoção dessa proposta poderá proporcionar ao paciente a manutenção de concentrações plasmáticas constantes aumentando assim as chances de uma resposta terapêutica mais efetiva, porém na prática clínica observa-se que a lavagem dos equipos no processo de infusão endovenosa de medicamentos não acontece (SILVA, FURLAN, e WEHBE, 2011).

A utilização de medicamentos em crianças em unidades de terapia intensiva pediátrica, geralmente tem como prevalentes o uso de medicamentos intravenosos e, na maioria dos casos, são medicamentos licenciados para adultos. Isso implica na necessidade de adaptação das formas farmacêuticas, várias diluições para se alcançar a concentração desejada para essa faixa etária. Com isso, o tratamento de crianças criticamente enfermas requer um cuidado especial a fim de 


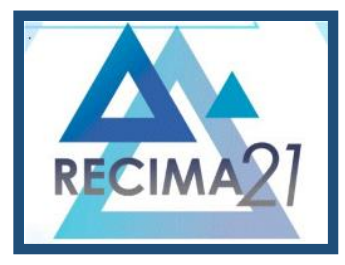

\section{RECIMA21 - REVISTA CIENTÍFICA MULTIDISCIPLINAR}

TÉCNICA DE LAVAGEM DE EQUIPOS APÓS ADMINISTRACÃO DE MEDICAMENTOS: ANÁLISE DE DIPIRONA EM VOLUME RESIDUAL POR VOLUMETRIA DE OXIRREDUÇÃO. Ana Laura de Oliveira Gondim, Maria Amélia Estrela Albergaria

serem evitados eventos adversos relacionados a medicamentos, a exemplo da diluição errônea de medicamentos potencialmente perigosos. Um cuidado importante no manejo de administração é realizar a lavagem de equipos intravenosos com soluções compatíveis. No geral, a indústria que produz esses materiais não traz informações específicas para a população pediátrica, que necessita de volumes pequenos a fim de evitar complicações decorrentes do excesso de volume (SOUZA JUNIOR, 2014).

Se faz necessário propor o volume de solvente para lavagem completa de equipos considerando que os volumes residuais de medicamentos podem interferir no tratamento do paciente. O objetivo do presente trabalho é determinar o volume necessário de solvente para lavar equipos de infusão volumétrica utilizados em unidades de terapia intensiva pediátrica preenchidos com solução injetável de dipirona.

\section{REVISÃO DE LITERATURA}

Os equipos ligam o frasco do medicamento aos dispositivos utilizados para a punção venosa os cateteres periféricos. Os tipos de equipo variam de acordo com os fabricantes, podendo ser diferentes quanto ao tipo de gotejamento, mas todos apresentam os componentes básicos e vários tipos de acessórios são utilizados para aumentar a eficiência e acurácia da infusão de soluções endovenosas (PHILLIPS, 2001).

A infusão de doses inferiores às prescritas por repetidas vezes levará a falha terapêutica colocando em risco a segurança do paciente. O que preocupa é que, quase sempre, a falha terapêutica é atribuída ao medicamento não sendo considerada a possibilidade de falha no preparo e administração do medicamento (MOTA et al., 2009).

Segundo Cooper, Rassam e Melhor (2018), drogas intravenosas (IV) são amplamente administradas e a subdosagem pode resultar na falha da terapia. O volume morto em conjuntos de administração é subestimado e muitas vezes não reconhecido pela equipe multidisciplinar.

Uma quantidade considerável de princípio ativo é perdida no final da infusão devido ao volume morto. A perda de medicamento pode ser um problema na segurança e eficácia da terapia, principalmente para medicamentos em que a dosagem é ajustada pelo peso corporal (PLAGGE et al., 2010)

Pacientes em unidades de terapia intensiva pediátrica muitas vezes recebem um grande número de medicamentos pela via parenteral. Frequentemente mais de um medicamento é administrado simultaneamente pelo mesmo equipo e, portanto, o risco de incompatibilidades físicoquímicas é relevante (GIKIC et al., 2000).

Incompatibilidade é uma reação físico-química que ocorre quando dois ou mais medicamentos são misturados e o produto dessa reação pode afetar a eficácia e segurança da terapia. As reações que ocorrem na solução nem sempre são visíveis a olho nu, podendo produzir 


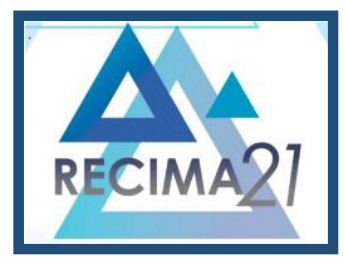

\section{RECIMA21 - REVISTA CIENTÍFICA MULTIDISCIPLINAR}

TÉCNICA DE LAVAGEM DE EQUIPOS APÓS ADMINISTRAC̄̃̃O DE MEDICAMENTOS: ANÁLISE DE DIPIRONA EM VOLUME RESIDUAL POR VOLUMETRIA DE OXIRREDUÇÃO. Ana Laura de Oliveira Gondim, Maria Amélia Estrela Albergaria

uma diminuição da eficácia ou um efeito adverso. A probabilidade de ocorrência de incompatibilidade aumenta em função do número de medicamentos associados, então, é necessário aumentar a vigilância e os cuidados (SECOLI, et al; 2009).

A incompatibilidade é considerada um erro associado ao uso de medicamentos, esse evento oferece risco ao paciente com possibilidade de causar dano, comprometendo a eficácia da terapêutica e interferindo de forma negativa na segurança medicamentosa (PAES et al., 2017). Conhecer os fundamentos das incompatibilidades pode ajudar a prevenir sua ocorrência e diminuir seus riscos (MORAES, SILVA e BUENO, 2011).

A dipirona está incluída na Relação Nacional de Medicamentos Essenciais (RENAME) na forma farmacêutica de comprimido, solução oral e injetável (BRASIL, 2018). É um analgésico e antipirético eficiente. É solúvel em água e se apresenta como um pó cristalino branco ou quase branco e inodoro. Por ser hidrossolúvel, pode ser administrado pela via parenteral em grandes doses, constituindo vantagem e, provavelmente, contribuindo para o uso excessivo deste fármaco, que é o analgésico e antipirético mais vendido no Brasil (KOROLKOVAS e BURCKHALTER, 1988).

A dipirona já foi descrita na literatura como o medicamento parenteral mais prescrito em uma unidade de internação pediátrica de um hospital universitário (SOUZA et al., 2008). A dipirona também foi o medicamento mais prescrito ( $88,3 \%$ dos pacientes) em cinco enfermarias pediátricas, de acordo com o estudo de um farmacêutico hospitalar. Sua principal indicação foi como antipirético, sendo $67,92 \%$ por via endovenosa (MEINERS e MENDES, 2001).

Para o doseamento de dipirona, o método indicado pela Farmacopeia Brasileira (2019) é a titulação de oxirredução direta com iodo (iodimetria) em meio ácido, utilizando solução indicadora de amido para determinação do ponto final. Embora outras técnicas para quantificação de dipirona estejam descritas na literatura, como a espectrofotometria ultravioleta/visível (UV/VIS), o método de titulação de oxirredução possui boa relação custo-benefício, é adequado para a análise do fármaco, além de ser o método preconizado pela agência reguladora (BICALHO, 2017; COSTA e LOPES, 2016).

\section{PROCEDIMENTOS METODOLÓGICOS}

Para este trabalho utilizou-se a metodologia de iodimetria, técnica preconizada pela ANVISA (BRASIL, 2019) para quantificação de dipirona. As análises consistem em determinar o volume mínimo necessário de soro fisiológico para lavar equipos de infusão volumétrica preenchidos com solução injetável de dipirona $(500 \mathrm{mg} / \mathrm{mL})$. As soluções foram armazenadas de acordo com as recomendações do fabricante até serem analisadas no laboratório de química e bioquímica do UNICEPLAC no Gama.

O doseamento consistiu em preencher o injetor lateral do equipo com a solução injetável de dipirona, que, em seguida, foi lavado com soro fisiológico, e a solução da lavagem coletada em 
TÉCNICA DE LAVAGEM DE EQUIPOS APÓS ADMINISTRAC̄̃̃ DE MEDICAMENTOS: ANÁLISE DE DIPIRONA EM VOLUME RESIDUAL POR VOLUMETRIA DE OXIRREDUÇÃO. Ana Laura de Oliveira Gondim, Maria Amélia Estrela Albergaria

frasco Erlenmeyer. Os volumes de soro usados foram variados entre um volume mínimo de $5 \mathrm{~mL}$ (volume entre o gotejador e o equipo conector para infusão no paciente) e incrementos de $5 \mathrm{~mL}$, até que não fosse detectada dipirona na solução de lavagem. A cada variação de volume testado, uma análise de detecção de dipirona foi realizada. Para detecção de dipirona foi feito um teste quantitativo a partir da solução coletada: adicionou-se $25 \mathrm{~mL}$ de água destilada, $5 \mathrm{~mL}$ de ácido acético glacial e homogeneizou-se por agitação. A titulação foi feita com iodo 0,04478 M SV (solução volumétrica) previamente padronizada, utilizando $1 \mathrm{~mL}$ de solução indicadora de amido. Os testes foram feitos em triplicata.

\section{RESULTADOS E DISCUSSÃO}

De acordo com a Farmacopeia Brasileira (2019), cada $\mathrm{mL}$ de iodo 0,05 M SV equivale a 17,57 mg de dipirona. Os cálculos foram realizados em planilhas do Microsoft Office Excel. Os resultados são apresentados no Gráfico 1, que mostra a concentração média de dipirona encontrada em relação ao volume de soro usado na lavagem do equipo.

As análises demonstraram que o volume de soro necessário para lavagem de equipos é de $15 \mathrm{~mL}$. Após a lavagem do equipo com esse volume, a dipirona não foi detectada na solução de lavagem, como demonstrado no Gráfico 1.

Gráfico1 - Resultado da análise de dipirona utilizando técnica de lavagem de equipos após preenchimento com solução injetável de dipirona

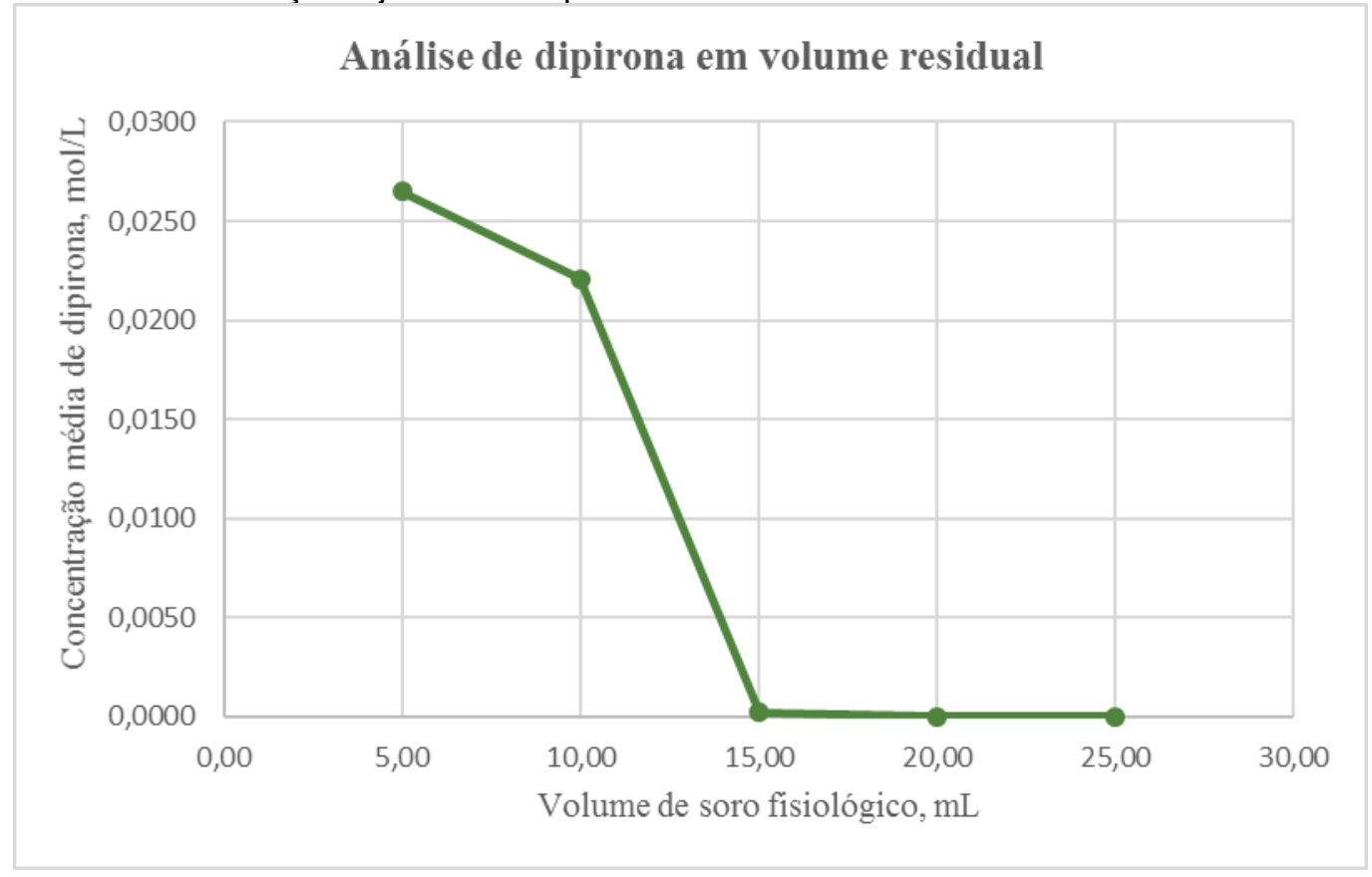




\section{RECIMA21 - REVISTA CIENTÍFICA MULTIDISCIPLINAR}

TÉCNICA DE LAVAGEM DE EQUIPOS APÓS ADMINISTRAÇÃO DE MEDICAMENTOS: ANÁLISE DE DIPIRONA EM VOLUME RESIDUAL POR VOLUMETRIA DE OXIRREDUÇÃO. Ana Laura de Oliveira Gondim, Maria Amélia Estrela Albergaria

Fonte: Do autor, 2020.

Os volumes de 5 e $10 \mathrm{~mL}$ não foram suficientes para a limpeza completa do equipo, pois foi identificada a presença de dipirona na solução de lavagem coletada, formando o volume residual que pode resultar em subdoses ou incompatibilidades.

A quantificação de dipirona após a lavagem do equipo foi obtida empregando-se o método de titulação de oxirredução direta com iodo (iodimetria) em meio ácido, método oficial de acordo com a Farmacopeia Brasileira volume 2, 6⿳亠丷厂 edição. A iodimetria é um método simples, rápido e fácil, além de utilizar instrumentação simples e barata. É importante destacar que não foi possível adotar uma técnica específica para lavagem da vidraria para as análises, pois esse material é de uso comum para pesquisa e ensino. A bureta foi calibrada e apresentou erro médio de $\pm 0,008 \mathrm{~mL}$, dentro do limite de tolerância do instrumento $( \pm 0,05 \mathrm{~mL})$.

A lavagem do equipo é fundamental para garantia da infusão completa do medicamento. No entanto, não é comum lavar os equipos no processo de infusão endovenosa de medicamentos. $O$ problema de subdose devido à presença do volume residual nos equipos pode ser minimizado adotando-se o equipo com bureta e preenchendo o equipo com $20 \mathrm{~mL}$ de soro fisiológico $0,9 \%$ ou solução compatível, permitindo a lavagem do equipo ao final da infusão do medicamento. Ressaltase a vantagem evidente de que tal processo traz a garantia de que todo o medicamento prescrito seja infundido, assegurando ao paciente uma resposta terapêutica mais efetiva, contribuindo, assim, para sua segurança (SILVA, FURLAN, WEHBE, 2011).

Hoefel e Lautert (2006), recomendam a adição de $20 \mathrm{~mL}$ de soro fisiológico ao final da dose intravenosa para lavagem do equipo. Afirma ainda, que não foi encontrada recomendação alternativa na literatura básica sobre o volume necessário para lavagem de equipo.

Leal, et al. (2016), ressaltou em seu estudo a prevalência elevada de incompatibilidades que não foram testadas, sendo a dipirona o principal medicamento envolvido. Não há interesse na publicação de estudos envolvendo dipirona em países como nos Estados Unidos, em função desse medicamento não ser comercializado nesses países. Já o fabricante indica que, devido à possibilidade de incompatibilidades, a solução de dipirona não deve ser administrada juntamente com outros medicamentos injetáveis (DIPIRONA SÓDICA, 1999).

A utilização de bombas de infusão inteligentes é um sistema de medicação seguro, porém, apresenta falhas e necessita de controle para que toda a dose seja administrada (HUSCH et al., 2005). Uma bomba seringa é útil onde seja necessária a injeção controlada, com elevada precisão de pequenos volumes como é o caso da pediatria, podendo assim, garantir a injeção do volume e doses adequados na terapia medicamentosa (MEDEIROS, 2018)

Os resultados encontrados no presente estudo nos indicam que $15 \mathrm{~mL}$ de soro fisiológico seja suficiente para lavagem do equipo, corroborando com o resultado de outros estudos (SILVA, FURLAN, WEHBE, 2011; HOEFEL e LAUTER, 2006). É importante ressaltar que a técnica utilizada 


\section{RECIMA21 - REVISTA CIENTÍFICA MULTIDISCIPLINAR}

TÉCNICA DE LAVAGEM DE EQUIPOS APÓS ADMINISTRACÃO DE MEDICAMENTOS: ANÁLISE DE DIPIRONA EM VOLUME RESIDUAL POR VOLUMETRIA DE OXIRREDUÇÃO. Ana Laura de Oliveira Gondim, Maria Amélia Estrela Albergaria

neste estudo é quantitativa, diferente do que foi feito em outros estudos relacionados a lavagem de equipos.

\section{CONSIDERAÇÕES FINAIS}

De acordo com o presente estudo o volume de soro necessário para lavagem de equipo é de $15 \mathrm{~mL}$. Após a lavagem do equipo com esse volume, a dipirona não foi detectada na solução de lavagem. Os volumes de 5 e $10 \mathrm{~mL}$ não foram suficientes para a limpeza completa do equipo. Pesquisas futuras devem se concentrar em volumes entre 10 e $15 \mathrm{~mL}$, para tentar diminuir ainda mais o volume necessário para lavagem de equipos em pediatria. É importante ressaltar que, sem protocolos norteadores sobre a importância e necessidade da lavagem de equipo, os riscos inerentes continuarão acontecendo.

\section{REFERÊNCIAS}

ANVISA. Agência Nacional de Vigilância Sanitária. Farmacopeia Brasileira. 6. ed. Brasília, 2019. v. 2.

BICALHO, A. B. Análise de qualidade por doseamento espectrofotométrico ultravioleta/visível (UV/VIS) e titulação por oxirredução de dipirona sódica comprimidos $500 \mathrm{mg}$. Revista Científica da Faminas, v. 12, n. 2, p. 15-27, 2017.

BRASIL. Ministério da Saúde. Secretaria de Ciência, Tecnologia e Insumos Estratégicos. Departamento de Assistência Farmacêutica e Insumos Estratégicos. Formulário Terapêutico Nacional Rename. Brasília, 2018. 218 p., il. (Série B. Textos Básicos de Saúde).

COOPER, D. M; RASSAM, T; MELHOR, A. Non-flushing of IV administration sets: an underrecognised under-dosing risk. British Journal of Nursing, v. 27, n. 14, p. 3-7, 2018.

COSTA, J. C.; et al. Identificação de Volume Residual em Seringas e Agulhas Após a Administração de Medicamento por Via Parenteral. Rev. Enferm. UERJ, Rio de Janeiro, v. 17, n. 3, p. 412-417, 2009.

COSTA, T. M. F.; LOPES, J. C. Controle de qualidade de soluções orais de Dipirona Sódica 500 $\mathrm{mg} / \mathrm{mL}$ referência, genérico e similar comercializadas em Gurupi-TO. Revista Amazônia Science \& Health, v. 4, p. 03-11, 2016.

DIPIRONA SÓDICA: injetável. Responsável técnico Andreia Cavalcante Silva: TEUTO, 1999. 1 bula de remédio (1p.).

GENNARO, A. R. Remington: a ciência e a prática da Farmácia. 20. ed. Rio de Janeiro: Guanabara Koogan, 2014.

GIKIC, M. et al. Evaluation of physicochemical incompatibilities during parenteral drug administration in a pediatric intensive care unit. Pharmacy world \& science. Chicago, v. 22, n. 3, p.88-91, 2000. 


\section{RECIMA21 - REVISTA CIENTÍFICA MULTIDISCIPLINAR}

TÉCNICA DE LAVAGEM DE EQUIPOS APÓS ADMINISTRAÇÃO DE MEDICAMENTOS: ANÁLISE DE DIPIRONA EM VOLUME RESIDUAL POR VOLUMETRIA DE OXIRREDUÇÃO. Ana Laura de Oliveira Gondim, Maria Amélia Estrela Albergaria

HOEFEL, H. H. K.; LAUTERT. L. Administração endovenosa de antibióticos e resistência bacteriana: responsabilidade da enfermagem. Revista eletrônica de enfermagem. Porto Alegre, v. 08, n. 03, p. 441-449, 2006.

$\mathrm{HUSCH}, \mathrm{M}$. et al. Insights from the sharp end of intravenous medication errors: implications for infusion pump technology. Quality and safety in health care. Chicago, v. 14, n. 02, p. 80-86. 2004.

KOROLKOVAS, A.; BURCKHALTER, J. H. Química Farmacêutica. São Paulo: Guanabara Koogan, 1988.

LEAL, K. D. B. et al. Potencial de incompatibilidade de medicamentos intravenosos em uma unidade pediátrica. Einstein. São Paulo, v. 14, n. 02, p. 185-189, 2016.

MEDEIROS, L. A. Desenvolvimento de uma bomba seringa com sistema de controle automatizado. Natal, 2018. 34 p. Dissertação (Trabalho de Conclusão de Curso) - Universidade Federal do Rio Grande do Norte, 2018.

MEINERS, M. M. M. A.; MENDES, G. B. Prescrição de medicamentos para crianças hospitalizadas: como avaliar a qualidade? Revista da associação médica brasileira. Brasília, v. 47, n. 4, p. $332-$ 337, 2001.

MORAES, C. G; SILVA, D; BUENO, D. Análise de incompatibilidades de medicamentos intravenosos no centro de tratamento intensivo adulto do hospital de clínicas de Porto Alegre. Revista HCPA. Porto Alegre, v. 31, n. 1, p.31-38, 2011.

MOTA, M. L. S. et al. Erros de dose relacionados a procedimentos de enfermagem na infusão endovenosa de antimicrobianos. Cogitare Enferm. Fortaleza, v. 14, n. 4, p. 653-659, 2009.

PAES, G. O; et al. Incompatibilidade medicamentosa em terapia intensiva: revisão sobre as implicações para a prática de enfermagem. Revista Eletrônica de Enfermagem. Rio de Janeiro, v. 19, n. 20, p.1-12, 2017.

PHILLIPS, L. D. Manual de terapia intravenosa. 2. ed. Porto Alegre: Artmed, 2001.

PLAGGE, H. et al. Evaluation of the dead volume in intravenous short-term Infusion. EJHP Science. Basel, Switzerland, v. 16, n. 2, p. 31-37, 2010.

PRELHACOSKI, D.; SILVA, D. M.; COMARELLA, L. Incompatibilidade medicamentosa em Unidade de Terapia Intensiva Pediátrica. Revista UNIANDRADE. Paraná, v.16, n. 2, p.73-81, 2015.

SANTOS, D. B. et al. Off-label and unlicensed drug utilization in hospitalized children in Fortaleza, Brazil. European journal of clinical pharmacology. Fortaleza, v. 64, n. 11, p.1111-1118, 2008.

SECOLI, S. R.; et al. Incompatibilidades en la terapia intravenosa: que hacer para prevenirlas? Rev. Enferm. Clin. São Paulo, v. 19, n. 2, p. 359-353, 2009.

SILVA, V. L. S.; FURLAN, M. L. S.; WEHBE, S. C. C. F. Identificação do volume residual em equipos de soluções parenterais após administração de medicamentos. Rev. Enferm. UERJ. Rio de Janeiro, v.19, n 2, p.192-197, 2011.

SOUZA JUNIOR, A. S. Estudo retrospectivo sobre o uso de medicamentos em neonatos internados em uma unidade de terapia intensiva neonatal em Brasília-DF. Brasília, 2014. 148p. Dissertação (Doutorado) - Universidade Federal do Ceará, 2014. 